\title{
Effectiveness of offline and online rewards in restoring satisfaction and trust
}

\section{Eficacia de las recompensas offline y online Para recuperar la satisfacción y la confianza}

\section{线下和线上奖励对恢复满意度和信任 的效果}

\author{
Zonaib Tahir \\ Quaid-i-Azam University, Islamabad, Pakistan
}

\begin{abstract}
Purpose - This paper aims to compare the relative importance of tangible compensation across the offline and online service mediums, and assess tangible compensation as a trust recovery tactic.

Methodology - This study is based on a 3 (compensation level: $20 \%, 50 \%, 100 \%) \times 2$ (compensation type: refund, coupon) $\times 2$ (service medium: offline, online) scenario-based experimental design.

Findings - The offline and online customers exhibit different satisfaction for the respective values of both the immediate and delayed compensation types. Moreover, offline customers exhibit more trust in the firm when they receive a refund, whereas their online counterparts demonstrate a higher trust when provided with a coupon.

Practical implications - For a service failure such as the one presented in the experimental study's scenario, a lower (higher) value coupon will generate more (less) satisfaction compared to providing the same value as a refund. Firms will be better off by providing partial compensation in the form of a coupon, rather than a refund.

Originality - Unlike most studies of service recovery, this research takes into account the perceived differences of various tangible compensations to provide a comparison of offline and online customers' recovery preferences. Furthermore, the previous studies have not focused on trust restoration and assessed
\end{abstract}

(C) Zonaib Tahir. Published in Spanish Journal of Marketing - ESIC. Published by Emerald Publishing Limited. This article is published under the Creative Commons Attribution (CC BY 4.0) licence. Anyone may reproduce, distribute, translate and create derivative works of this article (for both commercial and non-commercial purposes), subject to full attribution to the original publication and authors. The full terms of this licence maybe seen at http://creativecommons.org/licences/by/4.0/ legalcode

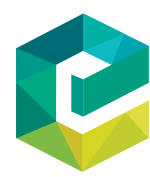

Spanish Journal of Marketing - 
SJME 25,3

causes and effects of trust based on trust at one point in time i.e. trust after recovery. While this study has included restored trust as a variable in the conceptual model.

Keywords Compensation, Trust, Customer relationship management, Service recovery, Online service recovery, Trust recovery

Paper type Research paper

\section{$410 \quad$ Resumen}

Propósito - Esta investigación tiene como objetivo comparar la importancia relativa de la compensación tangible en los medios de servicio offline y online, y evaluar la compensación tangible como táctica de recuperación de la confianza.

Metodología - Este estudio se basa en un diseño experimental basado en 3 (nivel de compensación: 20\%, $50 \%, 100 \%$ ) x 2 (tipo de compensación: reembolso, cupón) x 2 (medio de servicio: offline, online).

Conclusiones - Los clientes offline y online muestran una satisfacción diferente para los valores respectivos de los tipos de compensación inmediata y diferida. Además, los clientes offline muestran más confianza en la empresa cuando reciben un reembolso, mientras que sus homólogos online demuestran una mayor confianza cuando se les proporciona un cupón.

Implicaciones prácticas - Para un fallo del servicio como el presentado en el escenario del estudio experimental, un cupón de menor (mayor) valor generará más (menos) satisfacción en comparación con proporcionar el mismo valor como reembolso. Las empresas saldrán ganando si ofrecen una compensación parcial en forma de cupón, en lugar de un reembolso.

Originalidad - A diferencia de la mayoría de los estudios sobre la recuperación de servicios, esta investigación tiene en cuenta las diferencias percibidas de varias compensaciones tangibles para ofrecer una comparación de las preferencias de recuperación de los clientes offline y online. Además, los estudios anteriores no se han centrado en el restablecimiento de la confianza y han evaluado las causas y los efectos de la confianza basándose en la confianza en un momento determinado, es decir, la confianza después de la recuperación. En cambio, este estudio ha incluido la confianza restaurada como una variable en el modelo conceptual.

Palabras clave - Recuperación de servicio, Recuperación de servicio online, Compensación, Confianza, Recuperación de la confianza

Tipo de articulo - Trabajo de investigación

摘要

目的 - 本研究旨在比较有形补偿在离线和在线服务媒介中的相对重要性, 并评估有形补偿作为一种 信任恢复策略。

方法一本研究基于3（补偿水平： $20 \%, 50 \%, 100 \%$ ） ×2（补偿类型：退款, 优惠券） $\times 2 （$ 服务媒介： 线下, 线上) 的情景实验设计。

硏究结果 - 线下和线上的顾客对即时和延迟补偿类型的各自数值表现出不同的满意度。此外, 离线 顾客在收到退款时表现出对公司的更多信任, 而他们的在线顾客在得到优惠券时表现出更多的信任。

实际意义 - 对于像实验研究中提出的那种服务失败, 与提供相同价值的退款相比, 价值较低 (较高) 的优惠券会产生更多 (更少) 的满意度。企业通过以优惠券的形式提供部分补偿, 而不是退款, 会有 更好的效果。

原创性 - 与大多数关于服务恢复的研究不同, 这项硏究考虑到了各种有形补偿的感知差异, 以提供离 线和在线顾客恢复偏好的比较。此外, 以前的研究没有关注信任的恢复, 而是基于一个时间点的信任, 即恢复后的信任来评估信任的原因和影响。而本㸴究将恢复的信任作为概念模型中的一个变量。

关键词 - 服务恢复, 在线服务恢复, 补偿, 信任, 信任恢复

文章类型 - 㸴究型论文

\section{Introduction}

Trust is considered the foundation of relationship marketing but can be negatively impacted by service failures as they reduce a service provider's perceived reliability (Weun et al., 2004). In the context of service recovery, customer's trust depicts a positive expectation of the service failure 
resolution. Therefore, it is crucial for the firms to use appropriate recovery measures to restore trust after violations caused by service failures (DeWitt et al., 2008). However, the meta-analyses of Orsingher et al. (2010) and Gelbrich and Roschk (2011) specify that trust, in general, and trust recovery, in particular, has not been a focus of service recovery studies.

Customers' evaluation of the firm's recovery efforts is vital in rebuilding postfailure trust (La and Choi, 2012). There is an abundance of literature that used justice theory to identify compensation as most effective in rebutting the damaging effects of service failure (Gelbrich and Roschk, 2011; Orsingher et al., 2010). Yet, customers appear dissatisfied with organizational complaint handling as $65 \%$ of US complainants indicated that they get little in return upon complaining and more than one-half of complainants receive nothing [Customer Care Measurement and Consulting (CCMC), 2020]. Moreover, customers' evaluation of the service recovery not only depends on compensation's value but also the type, which is perceived differently because of its immediate or delayed nature (BambauerSachse and Rabeson, 2015). This suggests that the researchers and managers have to expend more effort toward ensuring satisfaction with service recovery efforts.

Despite examining the whole range of compensation, from low to high overcompensation, most of the service recovery studies have tested one or two levels of compensation, in combination with one or the other type, to test their causal relationships, for example, Smith et al., 1999 (50\%, 100\% discount), Roschk and Gelbrich, 2014 (100\% refund, $100 \%$ voucher). Hence, there is an opportunity of assessing compensation's relative importance for various levels of different types in a single study, not only for traditional failures but also the less explored online failures.

Surprisingly, the acceptance of the internet as a shopping medium has not induced considerable online service recovery research, especially when goods and money are not being exchanged simultaneously and the provision of sensitive personal information necessitates a higher initial trust in the online vendor, making it even more crucial to restore trust in case of service failures (Kim, 2014). Online service recovery research has thus far focused on the evaluation process (Collier and Bienstock, 2006) and produced a contradictory account of customers' recovery expectations (Jung and Seock, 2017). Having said that, it establishes that offline and online customers have different recovery expectations (Harris et al., 2006; Holloway and Beatty, 2003). However, the comparisons drawn have overlooked the perceived differences of various compensation types and their respective levels. Thus, there is scope to compare the offline and online customers' compensation preferences.

Customers expect the firms to make up for their tangible loss but compensation's role in restoring trust has not yet been assessed (Gelbrich and Roschk, 2011). The previous studies assessed trust at one point in time and positioned it as a mediating variable (Choi and La, 2013; DeWitt et al., 2008) or an attitudinal outcome of the customers' evaluations of the firm's recovery (Kau and Loh, 2006; Tax et al., 1998; Weun et al., 2004) but did not focus on its restoration. Therefore, in view of the gaps stated above, the overall aim of this research is to examine how compensation affects trust across offline and online service mediums, which has been addressed through a scenario-based experimental study. In the next section, literature related to service recovery and trust is discussed, which is followed by the hypotheses development section. The subsequent section presents the methodology, results and their discussion, after which the implications and limitations are outlined.

\section{Theoretical background}

\subsection{Customers' evaluation of service recovery}

It is prudent for the firms to use appropriate recovery efforts after the occurrence of a service failure because the defection of the dissatisfied customers can result in not only financial but 
also reputation loss (Nguyen et al., 2012). Customers' evaluation of service failure and recovery encounters depends on the type and amount of resources lost and gained during the exchange (Smith et al., 1999). Schoefer and Ennew (2005) mention that perceived justice is a useful and effective tool for understanding the emotional responses that a customer experiences during a service recovery.

Service researchers have extensively used justice theory to explain customers' reactions to service recovery (McColl-Kennedy et al., 2003; Smith et al., 1999). The interaction of the customer with the organization's employees, the procedures used by an organization to handle complaints and the outcomes of service recovery generate perceptions of justice. Consistent with the work in psychology, services marketing research has opted for a threedimensional approach to perceived justice, namely, distributive, procedural and interactional (Maxham and Netemeyer, 2002; Orsingher et al., 2010).

2.1.1 The relative importance of distributive, procedural and interactional justice. Distributive justice revolves around the perceived fairness of the recovery offered to the customer (Orsingher et al., 2010), procedural justice refers to the perceived fairness of the policies and procedures involving the recovery effort (Maxham and Netemeyer, 2002), and interactional justice is defined as the extent to which the customers feel they have been treated with respect, honesty and courtesy in their interactions with the organization (Smith et al., 1999).

Dissatisfied customers mostly want a replacement or compensation when they complain, as evident from most studies of post complaint satisfaction which show that distributive justice in the form of compensation has the utmost effect on customer satisfaction with recovery, repurchase intention and loyalty (Kau and Loh, 2006; Morrisson and Huppertz, 2010). The meta-analysis of Orsingher et al. (2010) and Gelbrich and Roschk (2011) further strengthen the premise that among the three dimensions of perceived justice, distributive justice has the strongest average correlation with satisfaction because customers expect the company to make up for their financial loss.

2.1.2 Compensation type and value. The existing literature classifies the compensation type as tangible and psychological compensation (Gelbrich and Roschk, 2011). Tangible compensation represents a material benefit such as a discount (Sparks and McColl-Kennedy, 2001), whereas psychological compensation denotes an emotional benefit that usually comes in the form of an apology (Davidow, 2003). Tangible compensation types are perceived differently because of their immediate or delayed nature (Bambauer-Sachse and Rabeson, 2015). The immediacy of the refund makes customers prefer it over a credit, however, those who are refunded may choose another service provider or simply keep the money (Gelbrich et al., 2014).

A credit may tempt customers to repurchase from the company to redeem the voucher (Roschk and Gelbrich, 2014) and there are studies that show positive effects of coupons on purchase intention (Sparks and McColl-Kennedy, 2001). However, the negative feelings generated by the service failure and the incurrence of extra charges to use the credit may make customers unwilling to visit again, thereby negating the purpose of delayed compensation (Kau and Loh, 2006; Noone, 2012). Bambauer-Sachse and Rabeson (2015), in their future research directions, noted that the contradictory support for both the immediate and delayed forms of compensation, and the lack of studies which combine these forms to deduce more effective compensation type make it worth investigating.

Compensation level or value is categorized as simple compensation (100\% or less) or overcompensation (more than 100\%) (Gelbrich and Roschk, 2011), where the value of the compensation offered should equate the value of the loss experienced to ensure satisfaction (Mattila, 2010). Smith et al. (1999) results showed that moderate recovery compensation has 
a greater effect on distributive justice perceptions than high compensation. However, a number of studies support a positive relationship of overcompensation with satisfaction (Hocutt et al., 2006). Having said that, overcompensation not only has a significantly lower incremental effect on satisfaction (Noone, 2012) but also raises concerns regarding its cost and return (Gelbrich et al., 2014).

2.1.3 Importance and specificities of online service recovery. Despite the importance of studying service failure and recovery in the context of online shopping and a clear understanding of the types of online service failure, there are only a few studies on the subject. This was unanticipated because recovery measures are even more important for online service failures than offline as the dissatisfied customers remain only a click away from switching to another e-tailer (Collier and Bienstock, 2006). Not to mention, customers can also record their displeasure on various electronic platforms, which is taken into account by the potential customers of any e-tailer (Van Vaerenbergh et al., 2019). With the buyer and seller physically separated during the transaction, recovery actions take on an added emphasis in regard to customer satisfaction (Holloway and Beatty, 2003).

Electronic retailers must contemplate when and how to respond to customers' complaints along with determining some form of compensation for the failure of the service (Jung and Seock, 2017). Importantly, previous research on online service recovery does not provide an insight into the relative importance of tangible compensation as the researchers have manipulated only one compensation in their experimental studies. The recovery tested by Harris et al. (2006) and Jung and Seock (2017) was a coupon of 10\% value, which leaves room for the other recovery types to be tested with varying levels as suggested by Harris et al. (2006) in their future research directions.

\subsection{Trust}

Service failures lead to higher levels of perceived uncertainty in the future performance of the service provider, which results in a higher need for trust toward the service provider. Most definitions of trust have been approached from two perspectives as follows: one views trust as a belief, confidence or expectation about an exchange partner's trustworthiness while the other views trust as one's reliance upon another due to his/her own vulnerability. This study has taken into account both the perspectives to define customer's trust as "the willingness to rely on the seller in a situation of uncertainty, based on the belief and confident expectations that the seller will satisfactorily perform a specific action important to the buyer" (La and Choi, 2012; Wang and Huff, 2007).

Service failure is one such situation of uncertainty where trust is strengthened if the companies are responsive in a way that recognizes customers' particular needs and affirms their sense of worth. Those of the dissatisfied customers who choose to complain, do so not only with the confidence that their grievances will be resolved in an equitable way but also in a manner that endorses their decision to enter into relationships with the firm in the first place. Therefore, if the complainants get a poor response from an organization, they are likely to perceive that organization as untrustworthy (De Matos et al., 2009; DeWitt et al., 2008).

2.2.1 Overview of trust in service recovery studies. As stated earlier, trust has been assessed as a key mediating variable and an attitudinal outcome in the service recovery literature (Choi and La, 2013; DeWitt et al., 2008; Kau and Loh, 2006; Weun et al., 2004; Tax et al., 1998), where the effects of justice perception on trust were examined but trust recovery measures have not been investigated. The meta-analyses of Orsingher et al. (2010) and Gelbrich and Roschk (2011) are reflective of this assertion. Evidently, there are only two studies that are devoted to determining the actions firms may take to restore consumer trust: 
SJME

25,3

414

Wang and Huff (2007) examined buyers' response to sellers' violation of trust, and Basso and Pizzutti (2016) showed that recovery from double deviations requires fundamentally different strategies than recovery from single deviations.

2.2.2 Online view of trust. Online retailing is an integral part of firms' multichannel strategy, however, the physical separation of the customer from the seller and the product, and the perceived insecurity of the internet make it challenging for online retailers to establish and maintain a long-term relationship with the customers. Internet purchasing entails uncertainty because the customers cannot physically examine the quality of a product, be assured of receiving the product as shown on the website or be certain of the security of their personal information, which makes trust a decisive factor (Mukherjee and Nath, 2007).

Customer trust is influenced by the perceived usability of the website, which may depend on the online retailer's reputation, the strength of the brand name, endorsement from trusted third parties and previous interactions on and/or offline. Furthermore, the fulfillment of expectations and secure handling of private data positively influence online customer trust (Casaló et al., 2008, 2011; Kim and Peterson, 2017). The degree of uncertainty in an online transaction is higher than that of a traditional transaction. The circumstances surrounding the online transactions not only differentiate online trust from the traditional view but also necessitate placing a higher initial trust in the online retailers (Kim, 2014), which makes it even more crucial to examine trust restoration for various online service failures.

\section{Hypotheses development}

\subsection{Satisfaction with compensation across the offine and online service mediums}

3.1.1 Effectiveness of compensation level. The recovery efforts of the organization must make customers believe that it has equitably made up for the loss bore by them. Dissatisfied customers mostly want a replacement or compensation when they complain, which is evident from most studies of post complaint satisfaction (Kau and Loh, 2006; Smith et al., 1999). Importantly, the value of compensation determines if the customers' perception of loss diminishes (Mattila, 2010). However, most of the service recovery studies used only one or two compensation levels, in combination with one or the other compensation type, to test their causal relationships (Smith et al., 1999: 50\%, 100\% discount; Mattila and Patterson, 2004: 20\% discount; Wirtz and Mattila, 2004: 20\% discount; Roschk and Gelbrich, 2014: $100 \%$ refund, $100 \%$ voucher). Though Gelbrich et al. (2014) studied the whole continuum of compensation from $0 \%$ to $200 \%$, they manipulated compensation in the form of credit only. Through this study, the motive is to first assess the effectiveness of compensation level, irrespective of the type, so as to deduce how the perception of loss being waned affects attitudes. Therefore, the following hypothesis is proposed:

H1. Compensation level will have a positive effect on satisfaction with service recovery.

3.1.2 Moderating effect of compensation type. Customers' evaluation of the service recovery also depends on the type of tangible compensation received (Smith et al., 1999), which is perceived differently because of its immediate or delayed nature. Both the refund, preferred for its immediacy and the coupon, offered to generate repurchase, have advocates and critics alike (Bambauer-Sachse and Rabeson, 2015). The contradictory support for the compensation types and their differing perception leads to the assessment of various levels of the immediate and delayed compensation to deduce the relative importance of tangible compensation. Hence, the following hypothesis is put forth:

H2. The positive effect of compensation level on satisfaction with service recovery will be moderated by the type of compensation. 
3.1.3 Interactive effect of the compensation type and the service medium. The circumstances surrounding the online failures are quite different from the factors typically at the root of traditional service failures (Holloway and Beatty, 2003). Therefore, the traditional recovery measures cannot be applied with absolute certainty. The limited research on online service recovery has focused on its evaluation process and the specific recovery measures that have been studied lack consensus. Notably, the online service recovery research has not tested a variety of tangible compensation (10\% coupon: Harris et al., 2006; Jung and Seock, 2017) so as to deduce its relative importance for the online customers. Even though online service recovery research establishes that offline and online customers have different recovery expectations (Harris et al., 2006; Holloway and Beatty, 2003), the comparisons drawn did not take into account the perceived differences of various compensations. The manipulation of a variety of tangible compensation in this research will allow not only the deduction of the relative importance of the tangible compensation for the online customers but also its evaluation if different compensations have a varying effect across both the offline and online service mediums. Therefore, the following hypothesis will be assessed:

H3. The positive effect of compensation level on satisfaction with service recovery will be moderated by the interactive effect of the compensation type and the service medium.

\subsection{Compensation as a trust recovery tactic}

3.2.1 Role of compensation level. Trust evolves with new experiences and is violated if the expectations of the customers are not met. The service recovery efforts are regarded as mechanisms through which the trust can be rebuilt (De Matos et al., 2009) and a firm is deemed trustworthy if the recovery expectations of the customers are met (La and Choi, 2012). In the service recovery context, trust has not been studied at large, which is probably why its position in the nomological network remains equivocal but importantly, trust recovery has not been a focus of the services literature.

Having said that, Wang and Huff's (2007) study serves as a first step toward trust restoration by understanding the nature of customer's response to trust violation. While Basso and Pizzutti (2016) examined trust restoration after a double deviation through apology and promise, where financial compensation was not found as effective, however, it should be noted that the participants of their study were only exposed to the double deviation scenario. Hence, the role of financial compensation as a trust recovery tactic is still to be studied for single deviations. Along with, the inclusion of trust in a few service recovery studies and its unclear position in the nomological network prompts the following hypothesis:

H4. Compensation level will positively restore trust in the company.

3.2.2 Trust restoration across the service mediums for immediate and delayed compensations' levels. Service firms are inherently and characteristically surrounded with uncertainty in their behaviors, which is amplified in online shopping because of the non-simultaneous exchange of goods and money and the personal and financial information being recorded (Kim, 2014). This requires a relatively higher initial trust in online retailers compared to offline, which when violated by service failures, needs to be restored. Customers expect a failure resolution that validates their decision to opt for the service provider in the first place (DeWitt et al., 2008). It is assumed that the differing characteristics of both the shopping mediums, coupled with the immediate or delayed nature of compensation will generate 
SJME

25,3

416

contrasting effectiveness of tangible compensation as a trust recovery tactic. The following hypotheses are proposed to test the aforementioned assumption:

H5. The effectiveness of compensation level in restoring trust in the company will be moderated by the type of compensation.

H6. The effectiveness of compensation level in restoring trust in the company will be moderated by the interactive effect of the compensation type and the service medium.

\subsection{Effect of satisfaction on restored trust}

The previous studies positioned trust as a mediating variable or an attitudinal outcome of the customers' evaluations of the firm's recovery but did not focus on its restoration. These studies assessed its causes and effects based on trust at one point in time i.e. trust after recovery. On the other hand, this study would include restored trust as a variable in the conceptual model. Along with assessing the direct effect of compensation on trust restoration, the study would test the effect of satisfaction with service recovery on trust restoration to establish which effect is stronger. Hence, the following hypothesis is put forth:

H7. Satisfaction with the service recovery will positively restore trust in the company.

The hypothesized relationships among the variables are visualized in Figure 1.

\section{Methodology, results and discussion}

\subsection{Methodology}

A scenario-based experimental study, 3 (compensation level: $20 \%, 50 \%, 100 \%$ ) $\times 2$ (compensation type: refund, coupon) $\times 2$ (service medium: offline, online) was devised to test the hypotheses. As the study is based on the activities associated with service failure and recovery that might unfold over days or weeks, an experimental research design will enable the compression of time. Furthermore, making customers recall actual service failures and

Figure 1.

Hypothesized relationships

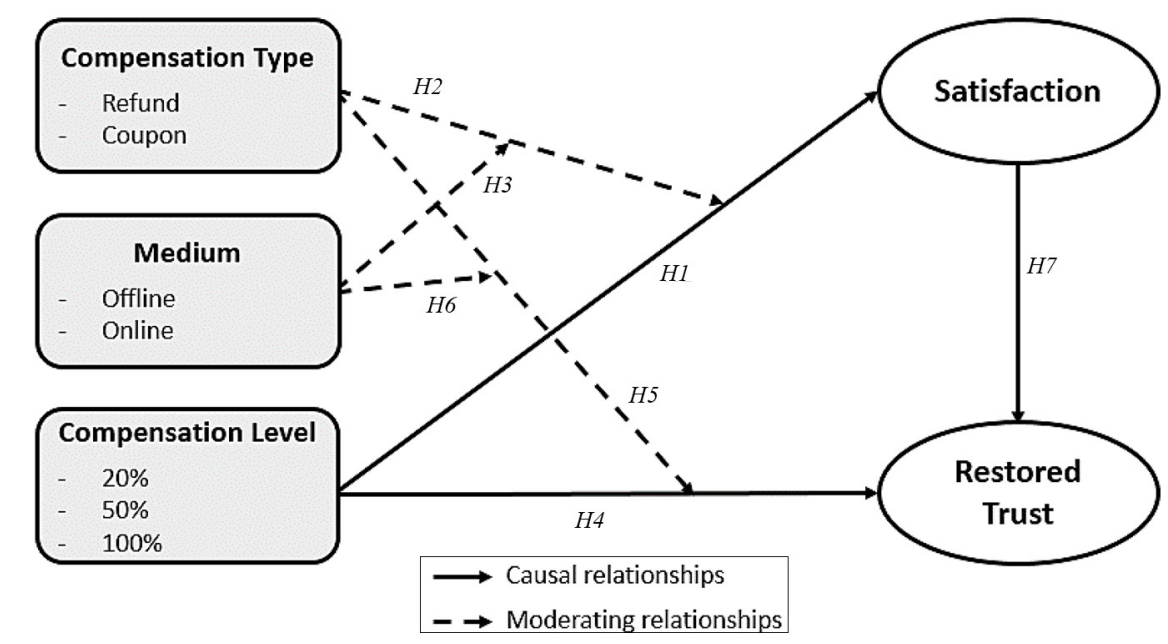


recoveries using a critical incident technique may increase response bias due to memory lapses or rationalization tendencies (Smith et al., 1999).

In total, 3 compensation levels will be tested: $20 \%$ as minimum or basic, $50 \%$ as moderate and $100 \%$ as the full compensation. As noted above, overcompensation has a low incremental effect, therefore, its effect will not be tested (Gelbrich and Roschk, 2011). Importantly, the motive behind testing the above mentioned compensation levels is to provide the practitioners with the most effective compensation level such that it would not raise concerns regarding the cost and return of such efforts (Gelbrich et al., 2014). Wirtz and Mattila (2004) branded a discount as a modest type of compensation and a gift might be perceived as a gesture of the service provider's concern for the service failure (BambauerSachse and Rabeson, 2015). Therefore, only refund and coupon are manipulated as the two compensation types in this study.

The service failure situation presented to the respondents draws inspiration from the scenario of Gelbrich et al. (2014) and outlines a post purchase failure involving a jacket, which is viewed as a service device (Vargo and Lusch, 2004, cited in Gelbrich et al., 2014). The hypothetical service failure is kept the same for both the offline and the online respondents to obtain an overall difference in terms of the recovery preferences and expectations (see Appendix). The questionnaire was distributed through SurveyMonkey and 1,573 complete responses were received. A total of 656 respondents were retained because they correctly answered the following memory-based manipulation check questions:

Q1. What did the store offer you in response to your complaint?Refund/Coupon

Q2. What percentage of the price was offered to you as compensation? $20 \% / 50 \% / 100 \%$

Q3. The jacket was bought from the:store/website.

A further 41 respondents were screened out because they were deemed multivariate outliers on the basis of mahalanobis distance. Response pattern checks led to the screening of a further 155 respondents for a usable sample of 460. The respondents had a mean age of 23.96 years (S.D. $=6.056$ ) and $49 \%$ were female.

Instead of developing a scenario based on a fictitious brand name, the respondents were first asked to state a clothing brand from where they will consider to buy a jacket for themselves to establish that the respondents have a certain level of trust in it. The respondents then answered questions that measured their trust before buying (T1) after which they were randomly assigned to 1 of the 2 service medium manipulations. They then read the service failure and answered questions that measured their trust after failure (T2). Each respondent then randomly received 1 of the 6 compensation manipulations and answered questions that measured their satisfaction with service recovery and trust after recovery (T3). The responses were recorded on a seven-point Likert-type scale.

4.1.1 Measures and manipulation check. The results of one-sample $t$-tests show that the respondents considered the scenario to be realistic $(\mathrm{M}=5.13, \mathrm{SD}=1.45, t=75.93, p<0.001)$ and were able to imagine themselves in the situation described in the scenario $(\mathrm{M}=5.44$, $\mathrm{SD}=1.30, t=89.73, p<0.001)$. Moreover, the scenarios describing the offline and the online purchase and the subsequent failure do not differ in terms of the scenario realism $\left(\mathrm{M}_{\text {store }}=\right.$ $5.16, \mathrm{SD}=1.42, \mathrm{M}_{\mathrm{website}}=5.10, \mathrm{SD}=1.49, t=0.46, p=0.43$ ).

A one-way analysis of variance revealed that the satisfaction was significantly different across the offline group's compensation conditions as follows: $20 \%$ Refund $(\mathrm{M}=3.55$, $\mathrm{N}=34), 50 \%$ Refund $(\mathrm{M}=4.35, \mathrm{~N}=38), 100 \%$ Refund $(\mathrm{M}=6.08, \mathrm{~N}=45), 20 \%$ Coupon $(\mathrm{M}=3.71, \mathrm{~N}=48), 50 \%$ Coupon $(\mathrm{M}=3.80, \mathrm{~N}=37)$ and $100 \%$ Coupon $(\mathrm{M}=5.52, \mathrm{~N}=42)$, $\mathrm{F}(5,238)=20.63, p<0.001$ and also across the online group's compensation conditions as 
SJME

25,3

418

follows: 20\% Refund ( $M=3.53, \mathrm{~N}=30), 50 \%$ Refund $(\mathrm{M}=4.36, \mathrm{~N}=31), 100 \%$ Refund $(\mathrm{M}=5.87, \mathrm{~N}=39), 20 \%$ Coupon $(\mathrm{M}=3.62, \mathrm{~N}=43), 50 \%$ Coupon $(\mathrm{M}=4.97, \mathrm{~N}=33)$ and $100 \%$ Coupon $(\mathrm{M}=5.63, \mathrm{~N}=40), \mathrm{F}(5,210)=18.65, p<0.001$.

Trust was operationalized through 6 items adapted from Garbarino and Johnson (1999), Chaudhuri and Holbrook (2001) and Sirdeshmukh et al. (2002) (T1: $\alpha=0.806$, T2: $\alpha=0.939$, T3: $\alpha=0.961)$. To assess the satisfaction with service recovery, Maxham and Netemeyer's (2002) scale was adapted $(\alpha=0.970)$. Kaiser-Meyer-Olkin and Bartlett's test confirm the adequacy of the sample. The results of Harman's single factor test indicate that the single factor accounts for $35 \%$ of the overall variance, which suggests that no common method variance bias is present that may affect the quality of the results (Podsakoff et al., 2003).

\subsection{Results}

Moderation model template 12 of Hayes's (2013) PROCESS macro was estimated to test the hypotheses. Restored trust was measured by calculating the difference between trust after recovery (T3) and trust before buying (T1). The effects of the independent and moderating variables on satisfaction with service recovery and restored trust, along with the conditional effects, are detailed in Tables 1 and 2.

\begin{tabular}{|c|c|c|c|c|}
\hline Manipulated variables and interactions & Effect & S.E. & $t(450)$ & $p$ \\
\hline Compensation level & 3.21 & 0.84 & 3.80 & $<0.001$ \\
\hline Medium & 1.80 & 1.24 & 1.45 & $0.15 \mathrm{~ns}$ \\
\hline Compensation level $\times$ medium & -1.23 & 0.54 & -2.27 & 0.02 \\
\hline Compensation type & 2.32 & 1.16 & 2.00 & 0.046 \\
\hline Compensation level $\times$ compensation type & -1.59 & 0.52 & -3.03 & 0.003 \\
\hline Medium $\times$ compensation type & -1.20 & 0.75 & -1.59 & $0.11 \mathrm{~ns}$ \\
\hline Compensation level $\times$ medium $\times$ compensation type & 0.86 & 0.34 & 2.56 & 0.01 \\
\hline \multicolumn{5}{|c|}{ Conditional effects of the focal predictor at values of the moderators } \\
\hline Compensation type & & & & \\
\hline Refund & 1.25 & 0.17 & 7.38 & $<0.001$ \\
\hline Coupon & 0.51 & 0.16 & 3.23 & 0.001 \\
\hline Refund & 0.87 & 0.18 & 4.87 & $<0.001$ \\
\hline Coupon & 1.00 & 0.16 & 6.15 & $<0.001$ \\
\hline
\end{tabular}

Table 1.

Effects on satisfaction with service recovery $\left(R^{2}=0.29\right)$

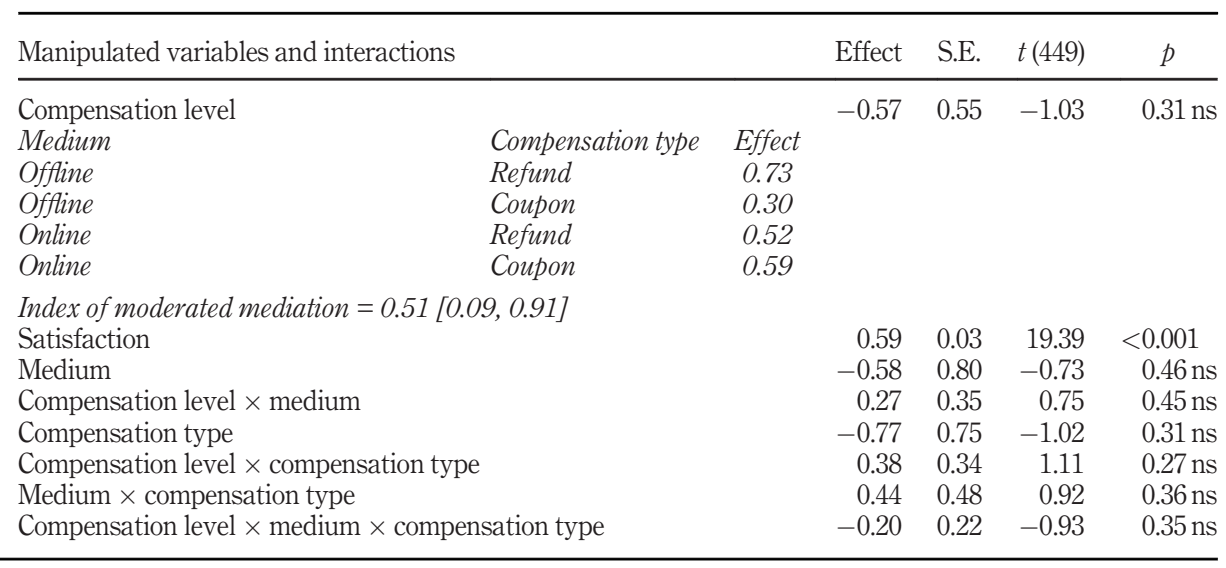

Table 2.

Effects on restored trust $\left(R^{2}=0.55\right)$

\section{Compensation level $\times$ medium $\times$ compensation type}




\subsection{Discussion}

The significant positive effect of compensation level on satisfaction shows that respondents' satisfaction varies with the compensation level (Table 1) such that more the compensation level, more will be the satisfaction, hence lending support to $H 1$. The support for both the immediate and delayed compensations in the service recovery literature led to the effectiveness' evaluation of either of the compensation types. It was also hoped that the relative importance of the different compensations, which were manipulated in the scenario, would be calculated. The significant interactive effect of "compensation level" and "compensation type" on "satisfaction" leads to the acceptance of $H 2$.

Even though, compensation type's significant effect on satisfaction $(\beta=2.32$, Table 1$)$ shows that coupon is preferred over a refund, the significant interactive effect of "compensation level" and "compensation type" shows that the differing satisfaction for the two compensation types depends on their respective value. The negative value of the interactive effect of "compensation level" and "compensation type" on "satisfaction" ( $\beta=-1.59$, Table 1$)$ allows the inference that a higher (lower) value coupon generates a lower (higher) satisfaction compared to a higher (lower) value refund (compensation type was coded as refund $=1$, coupon = 2) [Figure 2(a)].

The significant but negative interactive effect of "compensation level" and "service medium" on "satisfaction" ( $\beta=-1.23$, Table 1$)$ indicates that a higher value of compensation will lead to lesser satisfaction for online complainants compared to the offline appellants (service medium was coded as offline $=1$, online $=2$ ). This effect validates Harris et al.'s (2006) claim that online customers will be satisfied with less compared to their offline counterparts. Figure 2(b) portrays the satisfaction for the compensation levels across both the service mediums.

The interactive effect of the "compensation level," "medium" and "compensation type" on "satisfaction" is significant ( $\beta=0.86$, Table 1$)$ and lends support to $H 3$. Table 1 also portrays the conditional effects of the compensation level for respective service mediums and compensation types, which show that the refund generates a higher satisfaction for offline customers and the coupon leads to greater satisfaction for online customers. This suggests that the immediate or delayed nature of the compensation is perceived differently across both the service mediums, thereby extending the findings of Holloway and Beatty

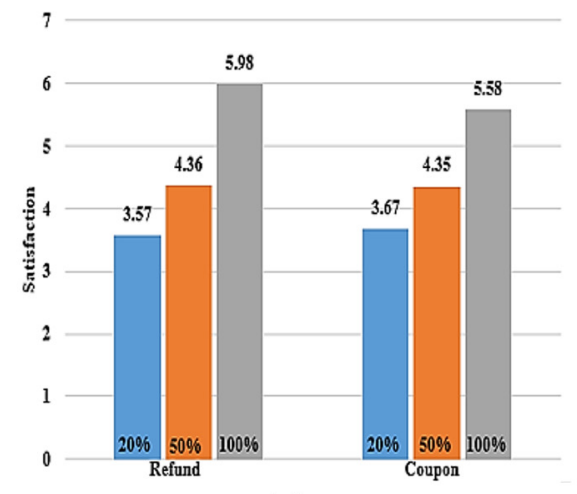

(a)

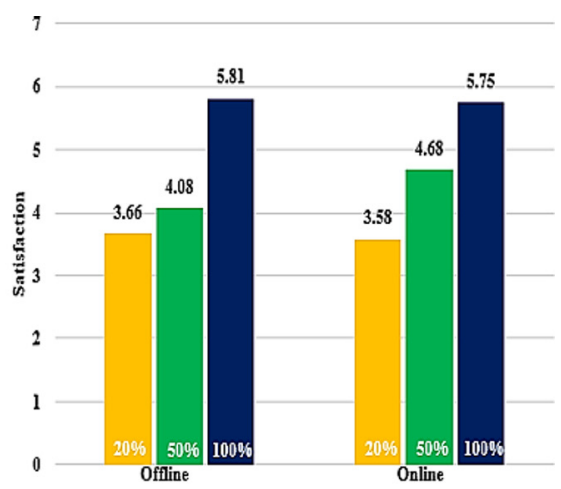

(b)
Figure 2. Satisfaction for respective

Notes: (a) values of refund and coupon; (b) compensation levels across service mediums 
SJME

25,3

(2003) and Harris et al. (2006), who suggested that the offline and online customers have different recovery expectations. Moreover, offline customers' preference for a refund augments the findings of Gelbrich et al. (2014).

The nonsignificant effect of compensation level on restored trust shows that the compensation level cannot directly restore trust in the company (Table 2), therefore, $H 4$ is rejected. The nonsignificant interactive effects of "compensation level and compensation type" and "compensation level, medium and compensation type" lead to the rejection of $H 5$ and H6. However, the significant conditional indirect effects of "compensation level" on "restored trust" show that a higher value refund recovers more trust of the offline customers, whereas more trust of online customers is recovered through a higher value coupon (Table 2). Moreover, the significant positive effect of satisfaction on restored trust (Table 2) supports $H 7$, which suggests that more the satisfaction, more will be the restored trust.

\section{Implications for theory and practice}

\subsection{Theoretical implications}

Despite lauding the role of service recovery efforts in restoring trust and customers' preference for tangible compensation, trust recovery has not been assessed at large. Addressing this gap is especially important because the inherent characteristics of online shopping necessitate a relatively higher initial trust in an online retailer compared to offline, which when violated, needs to be restored. Furthermore, the difference between the offline and online customers' recovery preferences is not based on a comparison of multiple compensation types or levels. Therefore, this research was aimed at comparing the relative importance of compensation across the offline and online service mediums and evaluating compensation's role in trust recovery.

5.1.1 Compensation level across service mediums. The negative value of the interactive effect of the "compensation level" and the "service medium" $(\beta=-1.19$, Table 1$)$ indicates that the online customers, compared to the offline customers, will portray a lesser satisfaction for a higher value compensation. This finding augments the assumption of Holloway and Beatty (2003) and Harris et al. (2006), who stated that the offline and online customers exhibit varying satisfaction with service recovery. This also leads to the inference that the online customers will be more satisfied with a relatively lower value of compensation compared to their offline counterparts e.g. 50\% instead of 100\% [Figure 2(b)]. This may be because online customers did not expend the same extent of physical effort as offline customers. They feel more in control of the transaction and perhaps blame themselves for the failure, which is why they probably were not expecting a lot in terms of compensation, hence, a lesser satisfaction for higher compensation. The offline customers, on the other hand, will demonstrate a comparatively higher satisfaction for a higher value compensation.

5.1.2 Immediate and delayed compensation across service mediums. The interactive effect of the "compensation level, type and the service medium" $(\beta=0.84)$ shows that the effectiveness of the immediate or delayed compensation, for their respective values, will be different across the offline and the online medium, such that the offline customers are more satisfied with a refund, whereas online customers exhibit more satisfaction for a coupon (Table 1). This finding augments the research of both Holloway and Beatty (2003) and Harris et al. (2006) where the former claimed online customers want more compensation while the latter advocated lower compensation. However, this research, unlike the aforementioned studies, took into account the perceived differences of the immediate and delayed compensation types to show that the offline and online customers exhibit different satisfaction for respective values of both the compensation types. 
This result leads to the inference that, as product and money are exchanged simultaneously in offline purchasing, the customers exhibit more satisfaction with an immediate compensation. While online purchasing entails a certain wait before the customer gets the product, therefore, the patience shown while waiting for the product's delivery reflects in the preference for delayed compensation. Moreover, coupons have been advocated to generate a higher repurchase intention (Sparks and McColl-Kennedy, 2001), which might also explain online customers' inclination toward a coupon as it will spur the continuation of internet shopping.

5.1.3 Trust restoration across service mediums. The study's results show that the compensation cannot directly restore trust in the company. However, the conditional indirect effects of compensation level on restored trust show that when the offline customers receive a refund, they exhibit relatively more trust in the firm, whereas when the online customers are provided with a coupon, they comparatively demonstrate a higher trust in the firm (Table 2). As per DeWitt et al. (2008), trust in case of a service failure is the expectation of a resolution, therefore, this finding contributes to the literature by demonstrating that the offline customers expect a refund, whereas the online customers expect a coupon for a service failure.

\subsection{Managerial implications}

The interactive effect of compensation level and type $(\beta=-1.55$, Table 1$)$ implies that a lower (higher) value coupon will generate more (less) satisfaction compared to providing the same value as refund [Figure 2(a)]. The experimental study's scenario highlighted that the product was used a few times before it became a liability. Therefore, providing a high value coupon may mean that the firm, without taking into account the usage context, simply wants the complainants to use the coupon, which may feel pushy or create an impression of a bribe. For such a failure situation, firms will be better off by providing a partial compensation in the form of coupon, rather than a refund.

The interactive effect of the compensation level, type and the service medium and the conditional effects of the compensation level (Table 1) show that the offline customers demonstrate more satisfaction for a refund and the online customers are more satisfied with a coupon. Refunding the offline customers entails a risk that they may not come back (Gelbrich et al., 2014), however, trusting customers by refunding and expecting them to come back might create a reciprocal effect and may lead to repurchasing. The key for the managers is to consider refund as an investment rather than a cost (Van Vaerenbergh et al., 2019).

However, the online customers' preference for a coupon can be explained through the demonstration of similar patience that they portray while waiting for the product delivery or expecting companies' response after filing a complaint. Besides, the online customers have an abundance of choices over the internet and they develop their own cues to assess and select a certain service provider, such as relying on the images to make up for the lack of physical inspection, and the product ratings and reviews of other customers. Perhaps, after investing ample time to gain online shopping expertise, they want to continue with it and receiving a coupon from a firm is perceived as an acknowledgment of their desire. It is pertinent that the firms proactively provide a coupon before receiving a complaint. Such an initiation is not only appreciated by the customers but also allows firms to make up for the lack of quality on the previous occasion (Xu et al., 2014). 
SJME

25,3

\section{Limitations and future research directions}

The future research can benefit from the inclusion of different service failure scenarios for both the service mediums based on their specificities, especially online. Furthermore, this study can be replicated with a longitudinal data to assess if the attitudes revealed over time generate the same results. Moreover, as the compensation levels manipulated in the scenario did not restore trust to the pre-failure levels, future studies may assess overcompensation in this regard.

\section{References}

Bambauer-Sachse, S. and Rabeson, L.E. (2015), "Service recovery for moderate and high involvement services”, Journal of Services Marketing, Vol. 29 No. 5, pp. 331-343.

Basso, K. and Pizzutti, C. (2016), "Trust recovery following a double deviation”, Journal of Service Research, Vol. 19 No. 2, pp. 209-223.

Casaló, L.V., Flavián, C. and Guinalíu, M. (2008), "Fundaments of trust management in the development of virtual communities", Management Research News, Vol. 31 No. 5, pp. 324-338.

Casaló, L.V., Flavián, C. and Guinalíu, M. (2011), "The generation of trust in the online services and product distribution: the case of spanish electronic commerce", Journal of Electronic Commerce Research, Vol. 12 No. 3, pp. 199-213.

Chaudhuri, A. and Holbrook, M.B. (2001), "The chain of effects from brand trust and brand affect to brand performance: the role of brand loyalty", Journal of Marketing, Vol. 65 No. 2, pp. 81-93.

Choi, B. and La, S. (2013), "The impact of corporate social responsibility (CSR) and customer trust on the restoration of loyalty after service failure and recovery", Journal of Services Marketing, Vol. 27 No. 3, pp. 223-233.

Collier, J.E. and Bienstock, C.C. (2006), "Measuring service quality in E-retailing”, Journal of Service Research, Vol. 8 No. 3, pp. 260-275.

Customer Care Measurement and Consulting (CCMC) (2020), "2020 National customer rage study", available at: www.customercaremc.com/insights/national-customer-rage-study/2020-nationalcustomer-rage-study/ (accessed 1 November 2021).

Davidow, M. (2003), "Organizational responses to customer complaints: what works and what doesn't", Journal of Service Research, Vol. 5 No. 3, pp. 225-250.

De Matos, C.A., Rossi, C.A.V., Veiga, R.T. and Vieira, V.A. (2009), "Consumer reaction to service failure and recovery: the moderating role of attitude toward complaining", Journal of Services Marketing, Vol. 23 No. 7, pp. 462-475.

DeWitt, T., Nguyen, D.T. and Marshall, R. (2008), "Exploring customer loyalty following service recovery: the mediating effects of trust and emotions", Journal of Service Research, Vol. 10 No. 3, pp. 269-281.

Garbarino, E. and Johnson, M.S. (1999), "The different roles of satisfaction, trust and commitment in customer relationships", Journal of Marketing, Vol. 63 No. 2, pp. 70-87.

Gelbrich, K. and Roschk, H. (2011), "A meta-analysis of organizational complaint handling and customer responses", Journal of Service Research, Vol. 14 No. 1, pp. 24-43.

Gelbrich, K., Gathke, J. and Gregoire, Y. (2014), "How much compensation should a firm offer for a flawed service? An examination of the nonlinear effects of compensation on satisfaction", Journal of Service Research, Vol. 18 No. 1, pp. 107-123.

Harris, K.E., Mohr, L.A. and Bernhardt, K.L. (2006), "Online service failure, consumer attributions and expectations", Journal of Services Marketing, Vol. 20 No. 7, pp. 453-458.

Hayes, A.F. (2013), Introduction to Mediation, Moderation, and Conditional Process Analysis: A Regression-Based Approach, The Guilford Press. 
Hocutt, M.A., Bowers, M.R. and Donovan, D.T. (2006), “The art of service recovery: fact or fiction?”, Journal of Services Marketing, Vol. 20 No. 3, pp. 199-207.

Holloway, B.B. and Beatty, S.E. (2003), "Service failure in online retailing: a recovery opportunity", Journal of Service Research, Vol. 6 No. 1, pp. 92-105.

Jung, N.Y. and Seock, Y. (2017), "Effect of service recovery on customers' perceived justice, satisfaction, and word-of-mouth intentions on online shopping websites", Journal of Retailing and Consumer Services, Vol. 37, pp. 23-30.

Kau, A. and Loh, E.W. (2006), "The effects of service recovery on consumer satisfaction: a comparison between complainants and non-complainants", Journal of Services Marketing, Vol. 20 No. 2, pp. 101-111.

Kim, D.J. (2014), "A study of the multilevel and dynamic nature of trust in e-commerce from a cross-stage perspective", International Journal of Electronic Commerce, Vol. 19 No. 1, pp. 11-64.

Kim, Y. and Peterson, R.A. (2017), "A meta-analysis of online trust relationships in e-commerce", Journal of Interactive Marketing, Vol. 38, pp. 44-54.

La, S. and Choi, B. (2012), "The role of customer affection and trust in loyalty rebuilding after service failure and recovery", The Service Industries Journal, Vol. 32 No. 1, pp. 105-125.

McColl-Kennedy, J.R., Daus, C.S. and Sparks, B.A. (2003), "The role of gender in reactions to service failure and recovery", Journal of Service Research, Vol. 6 No. 1, pp. 66-82.

Mattila, A.S. (2010), "Do women like options more than men? An examination in the context of service recovery", Journal of Services Marketing, Vol. 24 No. 7, pp. 499-508.

Mattila, A.S. and Patterson, P.G. (2004), "The impact of culture on consumers' perceptions of service recovery efforts", Journal of Retailing, Vol. 80 No. 3, pp. 196-206.

Maxham, J.G. and Netemeyer, R.G. (2002), “A longitudinal study of complaining customers' evaluations of multiple service failures and recovery efforts", Journal of Marketing, Vol. 66 No. 4, pp. 57-71.

Morrisson, O. and Huppertz, J.W. (2010), "External equity, loyalty program membership, and service recovery”, Journal of Services Marketing, Vol. 24 No. 3, pp. 244-254.

Mukherjee, A. and Nath, P. (2007), "Role of electronic trust in online retailing: a re-examination of the commitment-trust theory", European Journal of Marketing, Vol. 41 Nos 9/10, pp. 1173-1202.

Nguyen, D.T., McColl-Kennedy, J.R. and Dagger, T.S. (2012), "Matching service recovery solutions to customer recovery preferences”, European Journal of Marketing, Vol. 46 No. 9, pp. 1171-1194.

Noone, B.M. (2012), "Overcompensating for severe service failure: perceived fairness and effect on negative word of mouth intent", Journal of Services Marketing, Vol. 26 No. 5, pp. 342-351.

Orsingher, C., Valentini, S. and De Angelis, M. (2010), "A meta-analysis of satisfaction with complaint handling in services", Journal of the Academy of Marketing Science, Vol. 38 No. 2, pp. 169-186.

Podsakoff, P.M., MacKenzie, S.B., Lee, J. and Podsakoff, N.P. (2003), "Common method biases in behavioral research: a critical review of the literature and recommended remedies", Journal of Applied Psychology, Vol. 88 No. 5, pp. 879-903.

Roschk, H. and Gelbrich, K. (2014), "Identifying appropriate compensation types for service failures: a meta-analytic and experimental analysis", Journal of Service Research, Vol. 17 No. 2, pp. 195-210.

Schoefer, K. and Ennew, C. (2005), "The impact of perceived justice on consumers' emotional responses to service complaint experiences", Journal of Services Marketing, Vol. 19 No. 5, pp. 261-270.

Sirdeshmukh, D., Singh, J. and Sabol, B. (2002), "Consumer trust, value, and loyalty in relational exchanges”, Journal of Marketing, Vol. 66 No. 1, pp. 15-37.

Smith, A.K., Bolton, R.N. and Wagner, J. (1999), "A model of customer satisfaction with service encounters involving failure and recovery", Journal of Marketing Research, Vol. 36 No. 3, pp. 356-372.

Sparks, B.A. and McColl-Kennedy, J.R. (2001), "Justice strategy options for increased customer satisfaction in a services recovery setting", Journal of Business Research, Vol. 54 No. 3, pp. 209-218. 
SJME

25,3

Tax, S.S., Brown, S.W. and Chandrashekaran, M. (1998), "Customer evaluations of service complaint experiences: implications for relationship marketing", Journal of Marketing, Vol. 62 No. 2, pp. 60-76.

Van Vaerenbergh, Y., Varga, D., De Keyser, A. and Orsingher, C. (2019), "The service recovery journey: conceptualization, integration, and directions for future research", Journal of Service Research, Vol. 22 No. 2, pp. 103-119.

Vargo, S.L. and Lusch, R.F. (2004), "Evolving to a new dominant logic for marketing”, Journal of Marketing, Vol. 68 No. 1, pp. 1-17.

Wang, S. and Huff, L.C. (2007), "Explaining buyers' responses to sellers' violation of trust", European Journal of Marketing, Vol. 41 Nos 9/10, pp. 1033-1052.

Weun, S., Beatty, S.E. and Jones, M.A. (2004), "The impact of service failure severity on service recovery evaluations and post-recovery relationships", Journal of Services Marketing, Vol. 18 No. 2, pp. 133-146.

Wirtz, J. and Mattila, A.S. (2004), "Consumer responses to compensation, speed of recovery and apology after a service failure", International Journal of Service Industry Management, Vol. 15 No. 2, pp. 150-166.

Xu, Y., Marshall, R., Edvardsson, B. and Tronvoll, B. (2014), "Show you care: initiating co-creation in service recovery", Journal of Service Management, Vol. 25 No. 3, pp. 369-387.

\section{Appendix. Experimental study's scenario}

\section{Medium manipulation}

"Imagine that you went to the store/website of your brand and purchased the jacket from there. After sometime, you washed the jacket by carefully following the washing instructions. Unfortunately, the jacket shrunk and lost its shape, making it unwearable."

\section{Compensation manipulation}

"The failure prompted you to complain to the brand. In response to your complaint, they regretted the inconvenience and offered you a $20 \% / 50 \% / 100 \%$ Refund of the price of the jacket because the jacket was out of stock."

"The failure prompted you to complain to the brand. In response to your complaint, they regretted the inconvenience and offered you a Coupon worth $20 \% / 50 \% / 100 \%$ of the price paid for the jacket because the jacket was out of stock. The coupon can be used for your next purchase from the brand."

\section{Corresponding author}

Zonaib Tahir can be contacted at: zonaib@qau.edu.pk

For instructions on how to order reprints of this article, please visit our website: 